Article

\title{
Further Exploration of Sucrose-Citric Acid Adhesive: Synthesis and Application on Plywood
}

\author{
Shijing Sun ${ }^{1}\left(\mathbb{D}\right.$, Zhongyuan Zhao $^{2, *} \mathbb{C}$ and Kenji Umemura ${ }^{3, *}$ \\ 1 College of Material Science and Engineering, Nanjing Forestry University, Nanjing 210037, China; \\ sunsj-611@163.com \\ 2 College of Furnishings and Industrial Design, Nanjing Forestry University, Nanjing 210037, China \\ 3 Laboratory of Sustainable Materials, Research Institute for Sustainable Humanosphere, Kyoto University, \\ Kyoto 611-0011, Japan \\ * Correspondence: Zhaozy930@126.com (Z.Z.); Umemura@rish.kyoto-u.ac.jp (K.U.); \\ Tel.: +86-025-8542-7793 (Z.Z.); +81-0774-38-3652 (K.U.)
}

Received: 18 October 2019; Accepted: 11 November 2019; Published: 13 November 2019

\begin{abstract}
The development of eco-friendly adhesives is a major research direction in the wood-based material industry. Previous research has already demonstrated the mixture of sucrose and citric acid could be utilized as an adhesive for the manufacture of particleboard. Herein, based on the chemical characteristics of sucrose, a synthesized sucrose-citric acid (SC) adhesive was prepared, featuring suitable viscosity and high solid content. The investigation of synthesis conditions on the bond performance showed that the optimal mass proportion between sucrose and citric acid was $25 / 75$, the synthesis temperature was $100{ }^{\circ} \mathrm{C}$, and the synthesis time was $2 \mathrm{~h}$. The wet shear strength of the plywood bonded with SC adhesive, which was synthesized at optimal conditions and satisfied the China National Standard GB/T 9846-2015. The synthesis mechanism was studied by both ${ }^{13} \mathrm{C}$ NMR analysis and HPLC, and the chemical composition manifesting caramelization reaction occurred during the synthesis process. The results of ATR FT-IR indicated the formation of a furan ring, carbonyl, and ether groups in the cured insoluble matter of the SC adhesive, which indicated dehydration condensation as the reaction mechanism between sucrose and citric acid.
\end{abstract}

Keywords: eco-friendly adhesive; sucrose; citric acid; plywood

\section{Introduction}

The exploitation of bio-based composites has received increasing attention [1,2], however, the most widely utilized bio-based materials are traditional wood-based materials, for instance, particleboard [3], plywood [4], and fibreboard [5]. In the wood-based material industry, resins such as urea-formaldehyde, phenol-formaldehyde, and isocyanates are widely utilized due to their excellent adhesion properties and economically satisfactory performance [6]. However, these synthetic resins usually contain volatile organic compounds (VOC), which are harmful to human health $[7,8]$. Most of the raw materials of the synthesis resins are derived from fossil resources, and it is predictable that the utilization of these raw materials will be inevitably restricted in the future due to the depletion of fossil resources [9]. Therefore, the development of an eco-friendly wood adhesive composed of renewable materials has become a key topic of wood science $[10,11]$.

Previous research has already demonstrated that citric acid could be utilized as a green adhesive of wood-based materials [12-14]. In these studies, a citric acid water solution was sprayed on wood particles. After or without prior drying treatment, the sprayed particles were hot-pressed at $180-200{ }^{\circ} \mathrm{C}$ to fabricate particleboards. The mechanical properties and water resistance of the resulting particleboards satisfied the JIS A 5908 standard, and the reaction mechanism was considered to be the 
formation of carbonyl groups between citric acid and wood composition [14]. Furthermore, sucrose was added to the citric acid solution to promote bond performance $[15,16]$. However, although the previous citric acid-sucrose adhesive could be used for the manufacture of particleboard, it is rarely applied to the plywood production due to its low viscosity and low solid content. To overcome this limitation of the application of the citric acid-sucrose adhesion system, this study explores a synthesis method to gain a novel citric acid-sucrose adhesive with applicable viscosity, high solid content and good bond performance which satisfy the utilize requirements of plywood.

Sucrose ( $\beta$-D-fructofuranosyl $\alpha$-D-glucopyranoside) is a natural disaccharide, which is produced from sugar beet or sugarcane, and its chemistry has attracted considerable interest [17]. It is used as an organic raw material in the food, beverage, and seasoning industry since it is cheap, pure, stable, and chemically reactive [18-20]. Based on the research of sucrose chemistry, it is found that the heating treatment can transform sucrose into an amorphous substance along with increased solution viscosity, and acid compounds usually act as catalysts in this reaction [17,20-23]. Therefore, considering the chemical properties of sucrose and the reactivity of citric acid, there is a possibility to synthesize a suitable eco-friendly adhesive for plywood. This study investigated the effects of synthesis conditions on the bond performance of sucrose-citric acid (SC) adhesive and clarified its synthesis and curing mechanisms.

\section{Materials and Methods}

\subsection{Materials}

Sucrose (analytical reagent) and citric acid (analytical reagent) were purchased from Sinopharm chemical reagent Co., Ltd. (Shanghai, China), and used as received without further purification. The reagents were vacuum-dried at $60^{\circ} \mathrm{C}$ for $15 \mathrm{~h}$ until reaching a constant mass prior to usage in experiments. Poplar veneers were obtained from Zuogezhuang, Hebei Province, China.

\subsection{Preparation of Sucrose-Citric Acid (SC) Adhesives}

Sucrose and citric acid were mixed in different proportions and were poured into a three-mouthed flask with distilled water to synthesize SC adhesives with $80 \mathrm{wt} \%$ solid content. Three groups of adhesives were synthesized to investigate the effects of proportion, synthesis temperature, and synthesis time on the bond performance of plywood. All synthesis processes were conducted in an oil bath under $180 \mathrm{rpm} / \mathrm{min}$ mechanical stirring, and the detail information of the synthesis condition of each group are shown in Table 1. The $\mathrm{pH}$ values of the adhesives were measured at $30^{\circ} \mathrm{C}$ using a Leici pH meter PHBJ-206 (Leici, Shanghai, China). The viscosities of the adhesives were measured by HAAKE rotational rheometer MA S60 (HAAKE CO., Karlsruhe, Germany), in this test, $2 \mathrm{~mL}$ of each adhesive (without prior freeze-drying) was dripped on a flat plate, the measuring geometry was $\mathrm{C} 60$ $2^{\circ}$ /Ti-02170027, the temperature was $30^{\circ} \mathrm{C}$, and the testing mode was $\mathrm{CR}$ at a shear rate of $100 / \mathrm{s}$. Each viscosity test experiment was sustained for $300 \mathrm{~s}$ until the viscosity values tended to stabilize. A total of 80 viscosity measurements were acquired over the duration of analysis, while the final viscosity was defined as the average values of the last 40 data points. The results of $\mathrm{pH}$ and viscosity are shown in Table 1. All the synthesized SC adhesives were sealed and stored at room temperature for at least three days before further research was conducted involving them. 
Table 1. Detailed information of synthesis conditions and results of viscosity, $\mathrm{pH}$ values, and precipitation.

\begin{tabular}{|c|c|c|c|c|c|c|c|}
\hline Groups & $\begin{array}{c}\text { Mass } \\
\text { Proportion } \\
\text { (Sucrose/CA) }\end{array}$ & $\begin{array}{c}\text { Synthesis } \\
\text { Temperature } \\
\left({ }^{\circ} \mathrm{C}\right)\end{array}$ & $\begin{array}{l}\text { Synthesis } \\
\text { Time (h) }\end{array}$ & $\begin{array}{l}\text { Design Solid } \\
\text { Content (\%) }\end{array}$ & $\begin{array}{l}\text { Viscosity } \\
\text { (mPa s) }\end{array}$ & $\mathrm{pH}$ & $\begin{array}{l}\text { Whether Contain the } \\
\text { Precipitation after } \\
\text { 3 Days Storing }\end{array}$ \\
\hline \multirow{5}{*}{ Group 1} & $100 / 0$ & \multirow{5}{*}{90} & \multirow{5}{*}{3} & \multirow{5}{*}{80} & 1770 & 4.6 & Yes \\
\hline & $75 / 25$ & & & & 1690 & 1.5 & $\mathrm{NO}$ \\
\hline & $50 / 50$ & & & & 1290 & 1.2 & $\mathrm{NO}$ \\
\hline & $25 / 75$ & & & & 890 & 1.0 & $\mathrm{NO}$ \\
\hline & $0 / 100$ & & & & 20 & 0.9 & Yes \\
\hline \multirow{4}{*}{ Group 2} & \multirow{4}{*}{$25 / 75$} & 80 & \multirow{4}{*}{3} & \multirow{4}{*}{80} & 920 & 1.0 & $\mathrm{NO}$ \\
\hline & & 90 & & & 890 & 1.0 & $\mathrm{NO}$ \\
\hline & & 100 & & & 640 & 0.9 & NO \\
\hline & & 110 & & & 460 & 0.9 & $\mathrm{NO}$ \\
\hline \multirow{4}{*}{ Group 3} & \multirow{4}{*}{$25 / 75$} & \multirow{4}{*}{100} & 1 & \multirow{4}{*}{80} & 770 & 1.0 & $\mathrm{NO}$ \\
\hline & & & 2 & & 720 & 1.0 & $\mathrm{NO}$ \\
\hline & & & 3 & & 640 & 0.9 & $\mathrm{NO}$ \\
\hline & & & 4 & & 620 & 0.8 & $\mathrm{NO}$ \\
\hline
\end{tabular}

\subsection{Bond Performance}

\subsubsection{Manufacture of Plywood}

The synthesized SC adhesives were utilized to manufacture three-layer plywood (300 $\mathrm{mm} \times$ $300 \mathrm{~mm}$ ), the bond performance of which was evaluated. The moisture content and thickness of the veneers were $9.8-11 \%$ and $1.5 \mathrm{~mm}$, respectively. SC adhesives were applied to the core veneer at a spread rate of $140 \mathrm{~g} / \mathrm{m}^{2}$ for a single veneer surface. The coated veneer was stacked between two uncoated veneers so that the grain direction of both adjacent veneers was perpendicular to each other. All assembled three-layered plywood samples with each SC adhesive were hot-pressed at $190^{\circ} \mathrm{C}$ for $7 \mathrm{~min}$.

\subsubsection{Shear Strength Measurement}

The prepared plywood samples were cut into standard tensile shear test specimens according to China National Standards (GB/T 9846.7-2004). Six plywood specimens $(10 \mathrm{~cm} \times 2.5 \mathrm{~cm})$ were cut from each manufactured plywood and were submerged in water at $63 \pm 2{ }^{\circ} \mathrm{C}$ for $3 \mathrm{~h}$. Then, the tensile shear strengths of the plywood samples were measured at wet conditions at a loading rate of $1.0 \mathrm{~mm} / \mathrm{min}$. Each plywood was tested in six replications, and the average values, standard deviations, and average wood failure levels were calculated. Statistical significance was considered for $p$ values $<0.05$.

\subsection{Analysis of the Synthesis and Curing Mechanisms}

\subsection{1. $\mathrm{C}^{13}$ Nuclear Magnetic Resonance (NMR) Analysis}

$\mathrm{C}^{13} \mathrm{NMR}$ spectra were acquired on a Bruker AVANCE $600 \mathrm{MHz}$ spectrometer equipped with a $5 \mathrm{~mm}$ BBO probe using an inverse gated proton decoupling sequence. An amount of $100 \mathrm{mg}$ of freeze-dried SC adhesive was dissolved in $0.5 \mathrm{~mL}$ DMSO- $d 6$. Then, the solution was transferred to the Shigemi microtube and characterized at $25^{\circ} \mathrm{C}$. The acquisition parameters were $90^{\circ}$ pulse width, a relaxation delay of $1.7 \mathrm{~s}$, and an acquisition time of $1.2 \mathrm{~s}$. A total of 10,000 scans were collected.

\subsubsection{Attenuated Total Reflection-Fourier Transform Infrared Spectra (ATR-FTIR) Analysis}

ATR-FTIR spectra were acquired to assess chemical changes to (i) uncured SC adhesives (after freeze-drying) (ii) insoluble mass of SC adhesive with optimal synthesis conditions (obtained by curing at $190^{\circ} \mathrm{C}$ for $7 \mathrm{~min}$, then boiling in distilled water for $4 \mathrm{~h}$, and finally drying at $60^{\circ} \mathrm{C}$ for $15 \mathrm{~h}$ ). Infrared spectra were obtained using an ATR-FTIR spectrophotometer (Nicolet iS10, Thermo, Waltham, MA, USA), and were recorded with an average of 32 scans at a resolution of $4 \mathrm{~cm}^{-1}$. 


\subsubsection{High-Performance Liquid Chromatography (HPLC) Analysis}

The chemical composition of the synthesized SC adhesives from Groups 2 and 3 (without freeze-drying) were measured using Agillent 1260 high-performance liquid chromatography (HPLC; Agilent Technologies Inc., Santa Clara, CA, USA). Before the measurement, the adhesive solutions were diluted 300 times. The HPLC system was equipped with an HPX-87H ion exclusion column $(300 \mathrm{~mm} \times 7.8 \mathrm{~mm})$, degasser, pump, and refractive index (RI) detector. HPLC-grade milli-Q water was used as eluent at a flow rate of $0.6 \mathrm{~mL} / \mathrm{min}$ at a column temperature of $55^{\circ} \mathrm{C}$.

\section{Results and Discussion}

\subsection{Effects of Synthesis Conditions on Viscosity, pH Values, and Crystallization of SC Adhesives}

Table 1 shows the basic information of the SC adhesives. All results were measured after storing for three days at room temperature. The viscosity and $\mathrm{pH}$ of the synthesized adhesives of Group 1 decreased by adding citric acid, and crystallization could be observed in sucrose (100/0) and citric acid $(0 / 100)$ solutions. However, the crystalline components were not observed from the adhesives mixed with sucrose and citric acid, indicating that some reaction occurred during the synthesis treatment, and amorphous solutions formed, which prevented the crystallization [24]. With regard to the change of viscosity, due to the hydrolysis of sucrose, an amorphous substance with high viscosity was formed during the heat treatment [25], hence, the viscosity variation of adhesives showed a positive correlation with the sucrose proportion, although some crystallization could be found in the SC (100/0). In both Groups 2 and 3, the pHs of adhesives under all synthesis conditions were almost identical-this was due to the proportion of citric acid being constant. In contrast, the viscosity of Groups 2 and 3 decreased by increasing synthesis temperature and time, which was possible due to the formation of small molecule compounds (such as the monosaccharide and some conversion products [26]) during the heating process.

\subsection{Effects of Synthesis Conditions on the Bonding Performance}

To investigate the effects of different synthesis conditions on the bonding properties, the SC adhesives (prepared by various mass proportions, synthesis temperature, and synthesis times) were utilized to manufacture plywood at $190^{\circ} \mathrm{C}$ for $7 \mathrm{~min}$. Figure 1 shows the results of the wet shear strength of the plywood bonded by SC adhesives, which were synthesized with different mass proportions. The plywood manufactured by sucrose only (100/0) and 75/25 adhesives exhibited weak water resistance, and thus, the glue line broke in response to water immersion treatment. With increasing citric acid content to equal and higher than $50 \%$ conditions, the plywood showed a certain wet shear strength. The maximum bond strength was achieved by $25 / 75$ mass proportion adhesive $(0.78 \mathrm{MPa})$, which satisfied the China National Standard GB/T 9846-2015. In addition, the value of wood failure of the plywood bonded by $25 / 75$ adhesives showed a clear increase (45\%), which signified that the bonding strength between glue line and the wood surface was promoted. Other than the sucrose only condition, the plywood bonded by citric only (0/100) showed $0.35 \mathrm{MPa}$ wet shear strength and $35 \%$ wood failure, indicating that citric acid itself contributed to the bond strength and water resistance of plywood. These results demonstrate that the optimal mass proportion between sucrose and citric acid was 25/75. 


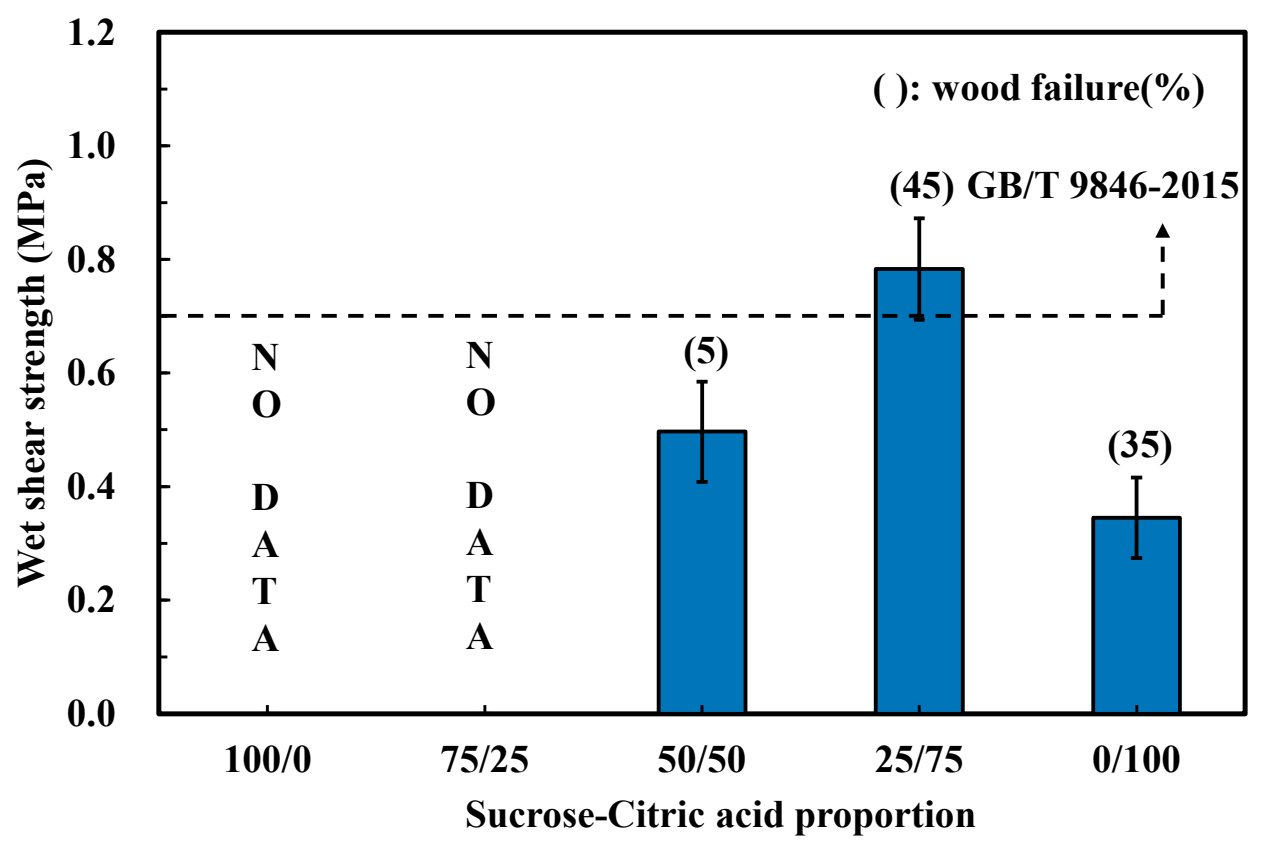

Figure 1. Effects of the mass proportion on the wet shear strength of plywood.

Figure 2 shows the results of the wet shear strength of the plywood bonded by the SC (75/25) adhesives, which synthesized at different temperatures. When the synthesis temperature increased from 80 to $100{ }^{\circ} \mathrm{C}$, both wet shear strength and wood failure were promoted, indicating that the bondability of SC adhesives was positively correlated with the synthesis temperature. The maximum value was $0.99 \mathrm{MPa}$, which was found for the plywood bonded with the adhesive synthesized at $100^{\circ} \mathrm{C}$. However, ANOVA analysis showed no significant difference in the wet shear strength between plywood bonded with SC adhesives synthesized at 100 and $110^{\circ} \mathrm{C}$. This implied that the influence of the synthesis temperature on the bonded strength of SC adhesive levelled off as the temperature exceeded $100{ }^{\circ} \mathrm{C}$. In addition, the wet shear strength of all specimens achieved the requirements of China National Standard GB/T 9846-2015. Judging from the bond performance of each synthesis temperature and considering room for improvement, the synthesis temperature at $100^{\circ} \mathrm{C}$ was considered as the optimal condition.

Figure 3 presents the effects of synthesis time on the bond performance of SC adhesives. Comparatively higher wet shear strengths were observed from plywood bonded by adhesives synthesized for $2 \mathrm{~h}(0.98 \mathrm{MPa})$ and $3 \mathrm{~h}(0.99 \mathrm{MPa})$. The results of the ANOVA analysis indicated that the bond strength between both types of adhesives was almost uniform. However, prolonging the synthesis time to $4 \mathrm{~h}$ caused significant decreases of both wet shear strength and wood failure, which was possibly attributed to the chemical transformation during the synthesis and curing processes. Consequently, judging from the bond performance of the plywood bonded with SC adhesives with different synthesis conditions, the optimal mass proportion between sucrose and citric acid, the synthesis temperature, and synthesis time were $25 / 75,100^{\circ} \mathrm{C}$, and $2 \mathrm{~h}$, respectively. 


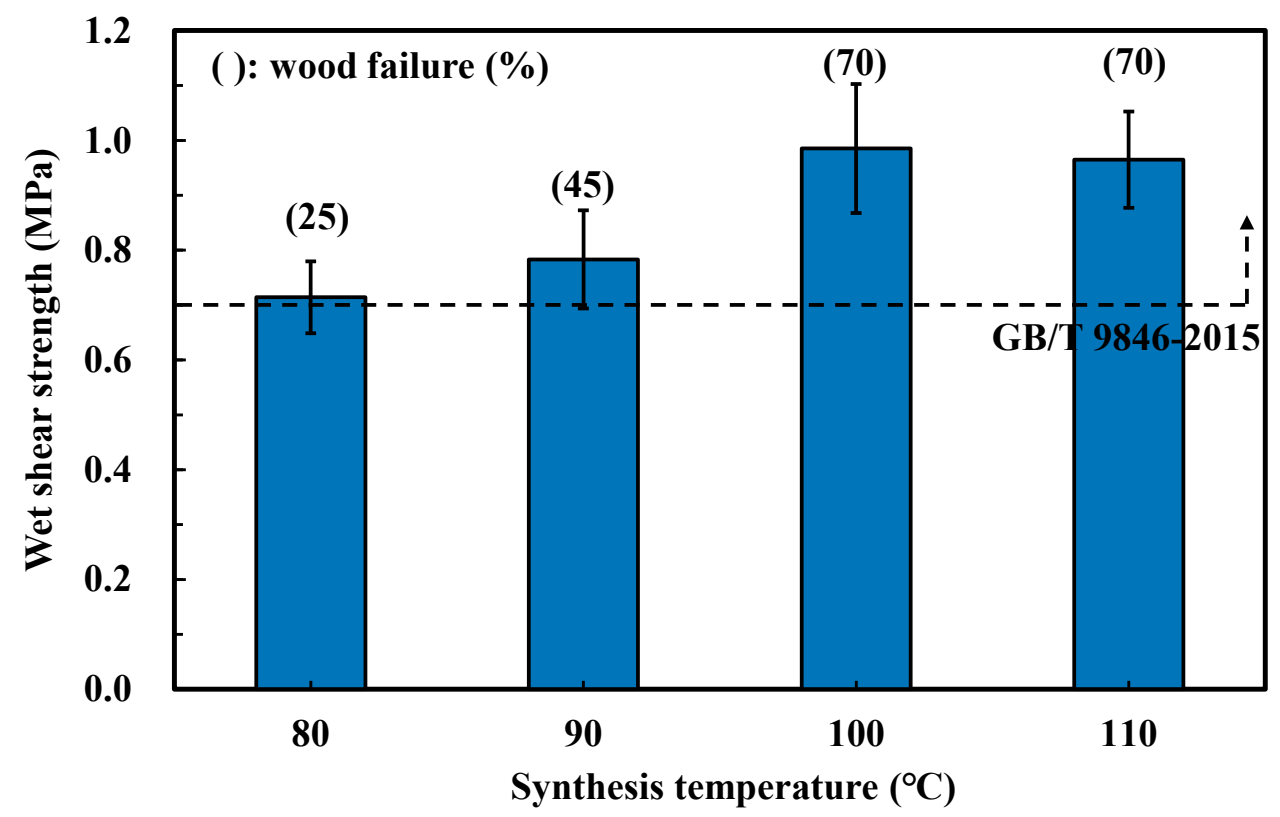

Figure 2. Effects of the synthesis temperature on the wet shear strength of plywood.

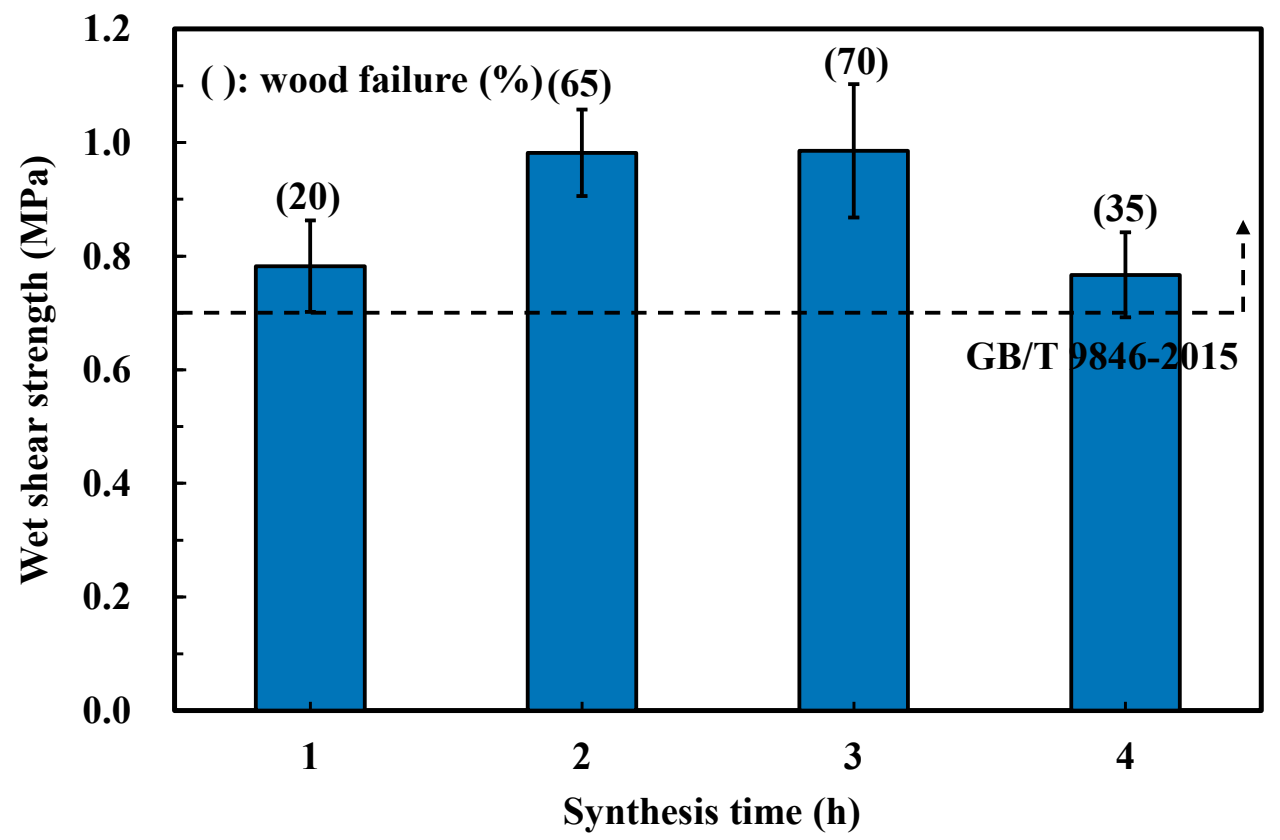

Figure 3. Effects of the synthesis time on the wet shear strength of plywood.

\subsection{Synthesis Mechanism}

\subsection{1. ${ }^{13} \mathrm{C}$ NMR}

To clarify the synthesis mechanism of SC adhesives, the ${ }^{13} \mathrm{C}$ NMR spectra of sucrose (100/0), SC adhesive (25/75), and citric acid (0/100), which were prepared at $100^{\circ} \mathrm{C}$ for $2 \mathrm{~h}$ were determined. The adhesive solutions were freeze-dried prior to the experiments. Figure 4 shows the chemical shift of sucrose (100/0). Two types of peaks can be observed, and the peak with higher intensity corresponded to sucrose $[27,28]$. In addition, the signals with lesser intensity were considered as the isomerides of glucose and fructose. The characteristic signals of $\mathrm{C} 1$ of glucose isomerides were observed at $97.1 \mathrm{ppm}$ ( $\beta$-D-glucopyranose), $92.5 \mathrm{ppm}(\alpha$-D-glucopyranose), $102.2 \mathrm{ppm}$ ( $\beta$-D-glucofuranose), and $98.3 \mathrm{ppm}$ ( $\alpha$-D-glucofuranose) [29-31]. With regard to the isomerides of fructose, the peaks at 64.7 and $64.01 \mathrm{ppm}$ 
were attributed to $\beta$-D-fructofuranose and $\alpha$-D-fructofuranose, respectively [29]. The presence of these signals confirmed the hydrolysis of sucrose during synthesis.

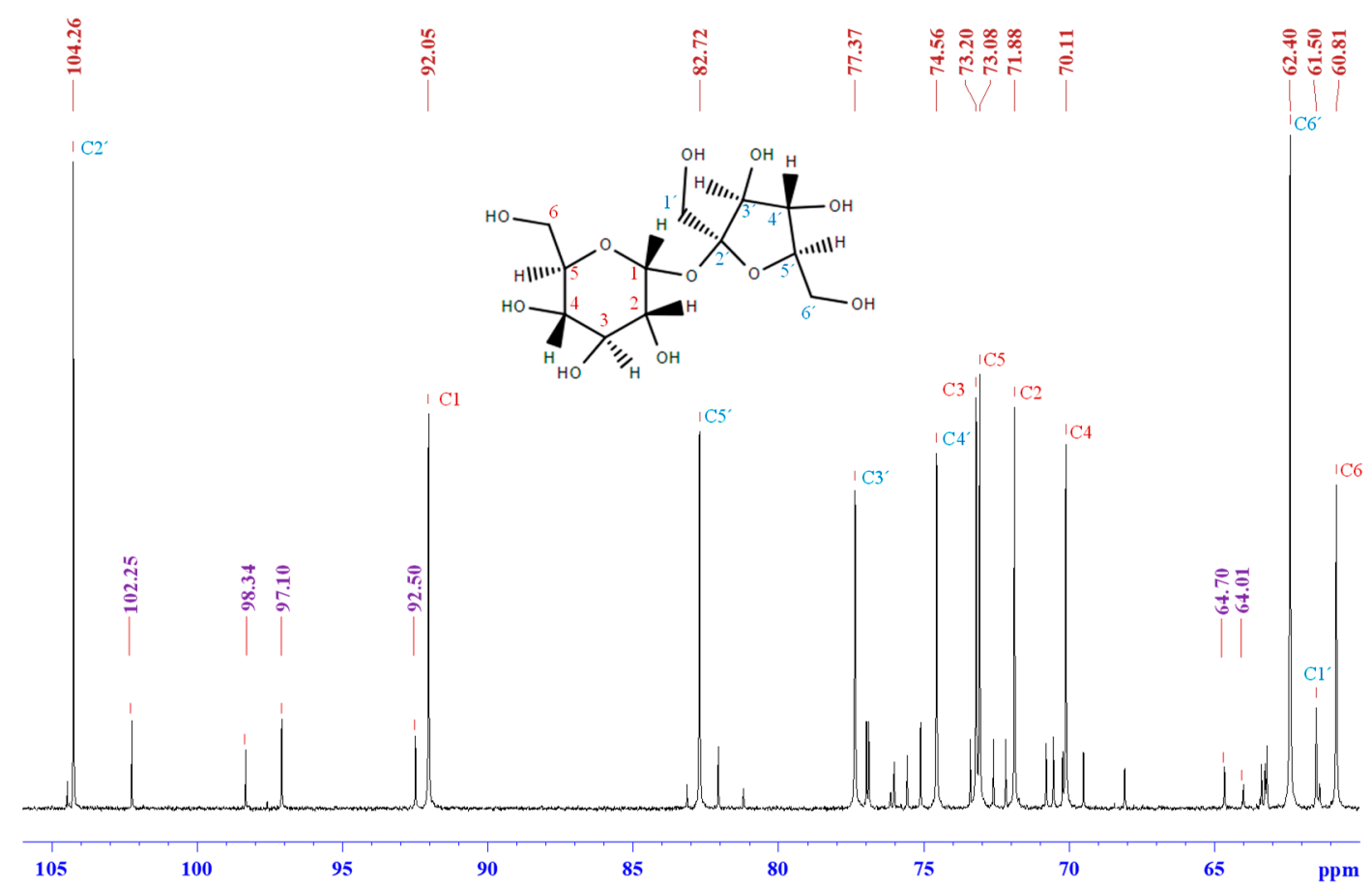

Figure 4. ${ }^{13} \mathrm{C}$ NMR spectrum of sucrose, prepared by synthesis process, as well as freeze dried and resolved in DMSO- $d_{6}$.

The ${ }^{13} \mathrm{C}$ NMR spectrum in Figure 5 shows the chemical shifts of citric acid only (0/100), where four high peaks can be attributed to $\mathrm{C} 1-\mathrm{C} 6$ of citric acid [32]. In contrast to sucrose, the specimen containing citric acid only indicated that synthesis treatment did not cause any chemical changes of citric acid. The ${ }^{13} \mathrm{C}$ NMR spectra of the 25/75 adhesive, as shown in Figure 6, indicates that the four higher-intensity signals were the result of the existence of citric acid, and the major peak area indicated that the principal compound in the 25/75 synthesized SC adhesive was citric acid. However, compared with the results shown in Figure 4, the characteristic peaks of sucrose disappeared, which implied that sucrose was transformed during the synthesis process. In the lesser intensity signals, the peaks located at 56.19, 152.00, 110.03, 125.37, 162.38, and 178.29 ppm were attributed to C1, C2, C3, C4, C5, and C6 of 5-hydroxymethylfurfural (5-HMF), respectively [33-35]. In addition, the resonances concentrated on 60-100 ppm were possibly attributed to oligosaccharides [36,37]. Based on the NMR analysis of the synthesized SC adhesives, the chemical composition of SC adhesive (25/75) differed from that of both sucrose (100/0) and citric acid (0/100). Furthermore, the existence of citric acid and the generation of 5 -HMF and oligomers indicated that caramelization of sucrose occurred during the synthesis process, in which, citric acid was considered the catalyst. 


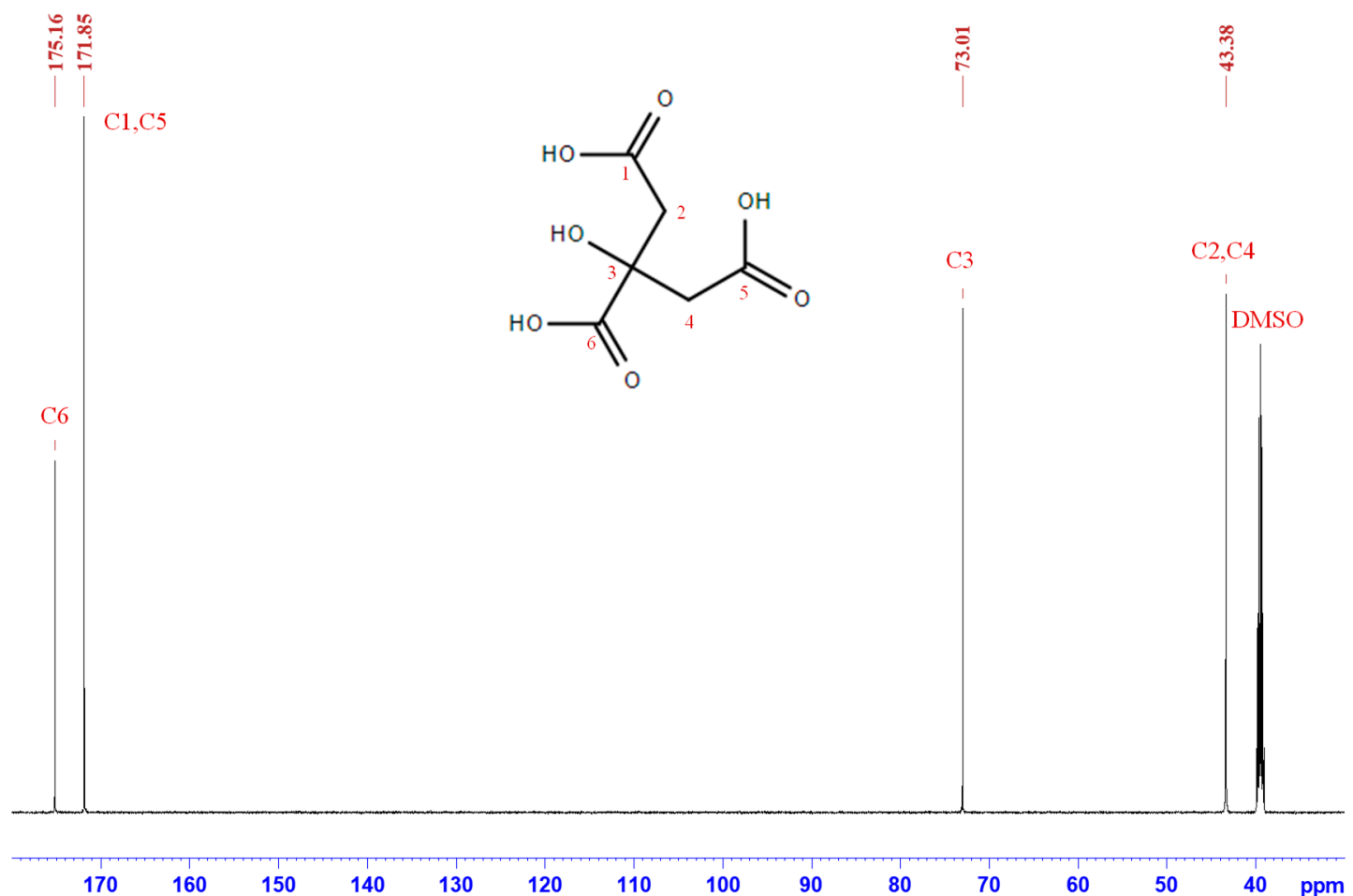

Figure 5. ${ }^{13} \mathrm{C}$ NMR spectrum of citric acid, prepared by synthesis process, as well as freeze dried and resolved in DMSO- $d_{6}$.

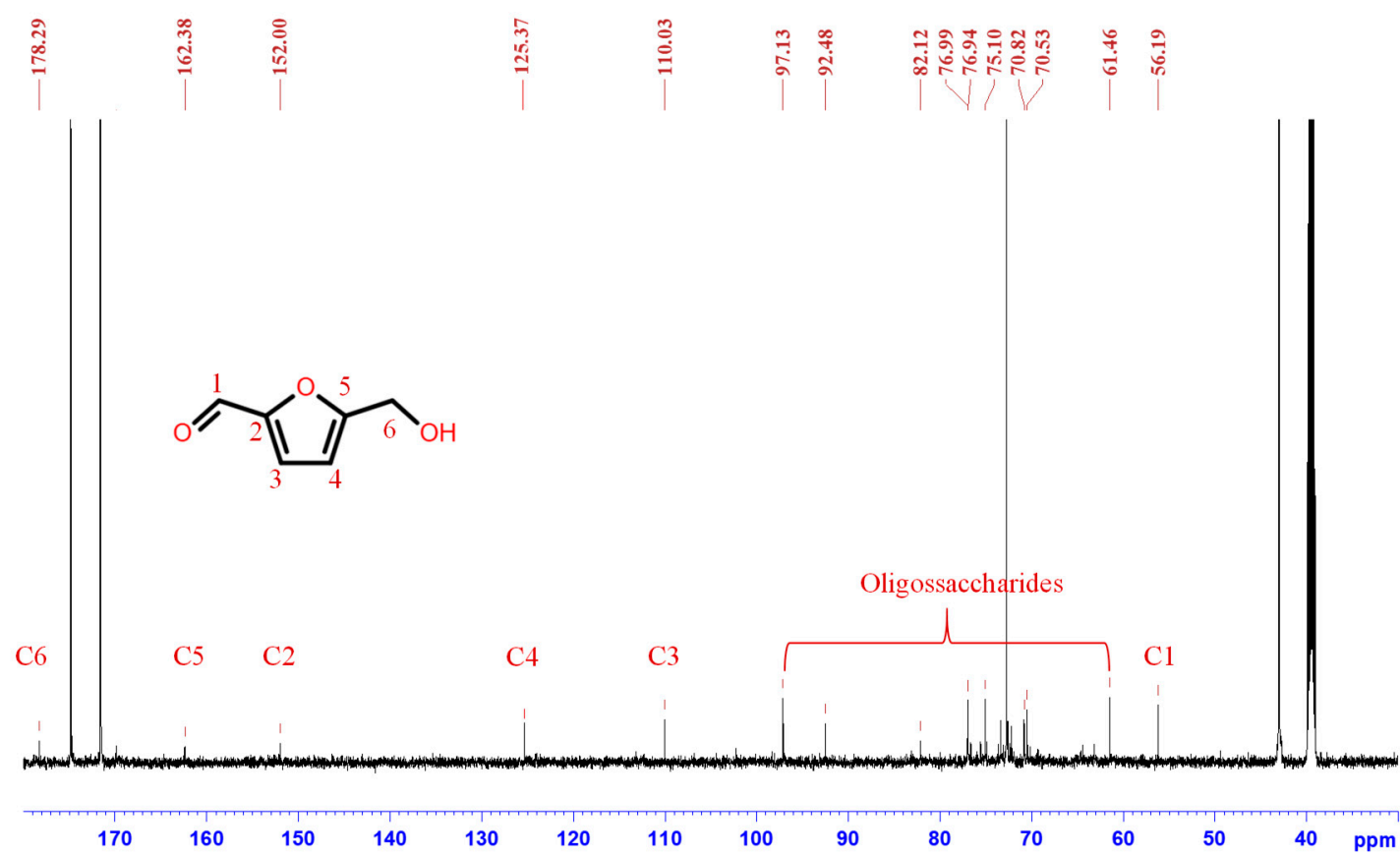

Figure 6. ${ }^{13} \mathrm{C}$ NMR spectrum of SC adhesive (25/75), prepared by synthesis process, as well as freeze dried and resolved in DMSO- $d_{6}$.

\subsubsection{HPLC}

To investigate the effects of synthesis conditions on the chemical composition of SC adhesives, the contents of glucose and 5-HMF of synthesized SC adhesives of Groups 2 and 3 were measured by HPLC. The results are shown in Table 2. In Group 2, the increase of synthesis temperature led to a reduction of glucose concentration and an increasing of 5-HMF, which was due to the hydrolysis 
of sucrose and the dehydration of monosaccharide. In Group 3, the content of glucose decreased in response to prolonged synthesis time. However, the concentration of 5-HMF increased from synthesis time at $1-3 \mathrm{~h}$ but decreased at $4 \mathrm{~h}$, which was possible because 5 -HMF converted to other oligomers, and this was considered as a reason for the reducing of bond strength in Figure 4. Focusing on the change of 5-HMF, clear growth was observed when the synthesis temperature was increased to $100^{\circ} \mathrm{C}$ (Group 2) and $2 \mathrm{~h}$ (Group 3). Judging from the results of the bonding performance of Groups 2 and 3, the maximum wet shear strength of the plywood bonded with SC adhesives along with the highest concentration of 5-HMF, indicated that the bonding properties of SC adhesives exhibited a positive correlation with the 5-HMF concentration.

Table 2. HPLC results of SC adhesive with 25/75 proportion synthesized under different temperatures and times.

\begin{tabular}{|c|c|c|c|c|c|}
\hline Groups & Sucrose-CA & Synthesis Temperature $\left({ }^{\circ} \mathrm{C}\right)$ & Synthesis Time (h) & Glucose (g/L) & 5-HMF (g/L) \\
\hline \multirow{4}{*}{ Group 2} & \multirow{4}{*}{$25 / 75$} & 80 & \multirow{4}{*}{3} & 50.7 & 1.5 \\
\hline & & 90 & & 46.2 & 2.9 \\
\hline & & 100 & & 41.2 & 8.2 \\
\hline & & 110 & & 34.5 & 9.8 \\
\hline \multirow{4}{*}{ Group 3} & \multirow{4}{*}{$25 / 75$} & \multirow{4}{*}{100} & 1 & 50.4 & 2.7 \\
\hline & & & 2 & 47.7 & 7.8 \\
\hline & & & 3 & 41.2 & 8.2 \\
\hline & & & 4 & 36.4 & 5.79 \\
\hline
\end{tabular}

\subsection{Curing Mechanism}

The chemical changes of SC adhesive before and after curing were measured by FT-IR, and the result at the $1800-500 \mathrm{~cm}^{-1}$ region is shown in Figure 7. Compared with uncured adhesive, four new peaks were generated and one peak disappeared from the cured adhesive. The new peak was located at $1722 \mathrm{~cm}^{-1}$ and could be attributed to $\mathrm{C}=\mathrm{O}$ stretching derived from carbonyl group and/or ester group [16,38]. The peak that disappeared at $1708 \mathrm{~cm}^{-1}$ was due to the $\mathrm{C}=\mathrm{O}$ of the carboxyl group [39]. Considering the chemical composition of the synthesized SC adhesive and the involved chemical changes, the formation of a novel $\mathrm{C}=\mathrm{O}$ group was possible due to the reaction between citric acid and 5-HMF. The peaks at 1514 and $797 \mathrm{~cm}^{-1}$ were derived from the $\mathrm{C}=\mathrm{C}$ stretching vibration and the $\mathrm{CH}=\mathrm{CH}$ of the furan ring $[40,41]$, respectively, indicated that furan compounds participated in the curing reaction. Another new peak located at around $1025 \mathrm{~cm}^{-1}$ was identified as the ether linkage C-O-R [42], which possibly formed by the dehydration condensation of furan compounds. In addition, several studies reported that citric acid could react with the hydroxyl group of wood components, which contributed to the bond strength $[14,43]$. Our results also corroborate this phenomenon (Figure 1). Therefore, the curing mechanism of SC adhesive for the manufacture of plywood should be described via two aspects: one is the dehydration condensation reaction between citric acid and the 5-HMF which derived from the sucrose caramelization, in which, the carbonyl and ether groups formed as cross-linkage; the second is the reaction between citric acid and wood components.

Based on the chemical analysis above, a possible synthesis mechanism and curing mechanisms are shown in Figure 8. In the synthesis process, 5-HMF and oligosaccharides were formed during the heating treatment, which implied the caramelization reaction as one considered as a synthesis mechanism. During the curing process, the furan ring, carbonyl group, and ether linkage were observed in the cured insoluble matter, and these chemical groups indicated that a dehydration condensation reaction occurred between citric acid and 5-HMF. In addition, the reaction between citric acid and wood constituents also contributed to the bond strength and water resistance of the resultant plywood. 


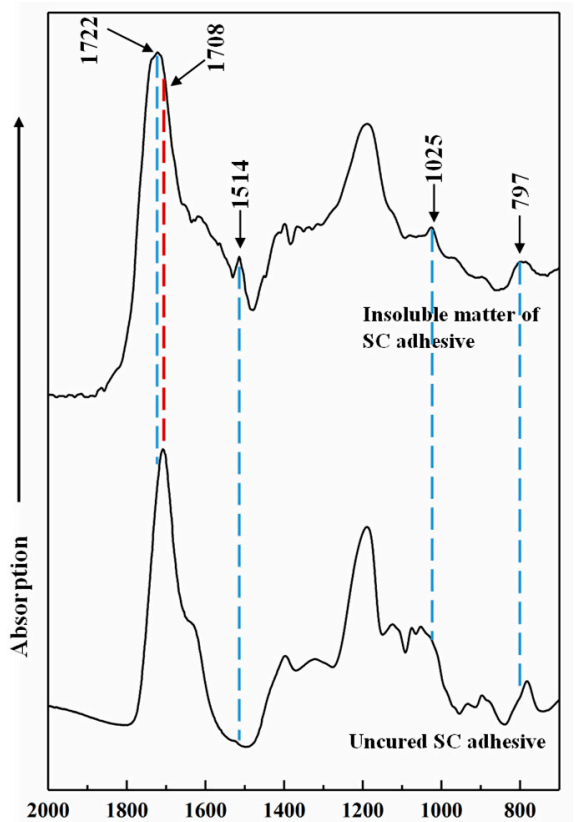

Figure 7. FT-IR spectrum of uncured and insoluble matter of SC adhesive (25/75).

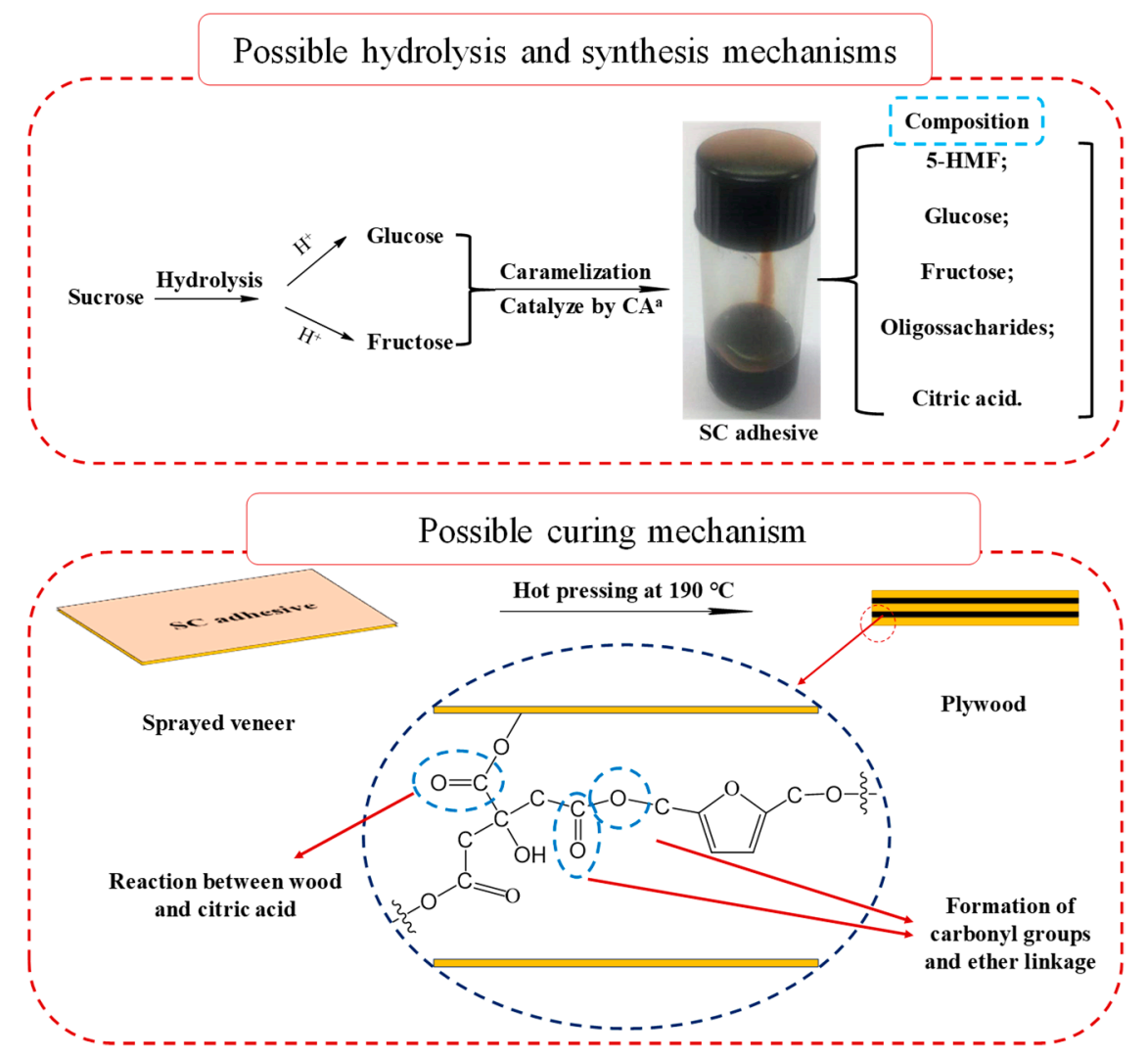

Figure 8. Possible synthesis and curing mechanism of SC adhesive. ( ${ }^{a}$ CA: Citric acid).

\section{Conclusions}

A novel eco-friendly adhesive was synthesized by combining sucrose and citric acid under heating conditions for incorporation into plywood. The effects of different synthesis conditions (such as mass proportion, synthesis temperature, and synthesis time) on the bonding performance of plywood were investigated. The results of wet shear strength tests indicated that the optimal synthesis conditions of SC adhesive were $25 / 75$ sucrose/citric acid mass proportion, $110^{\circ} \mathrm{C}$, and $2 \mathrm{~h}$. When plywood was 
bonded with the optimal SC adhesive at $170{ }^{\circ} \mathrm{C}$ for $7 \mathrm{~min}$, the wet shear strength achieved the China National Standard GB/T 9846-2015. The results of ${ }^{13} \mathrm{C}$ NMR and HPLC showed that 5-HMF and oligosaccharides were generated during the heating treatment. ATR FT-IR indicated the chemical structure change from uncured SC adhesive to cured insoluble matter. Compared with uncured SC adhesive, the furan ring, carbonyl group, and ether linkage were observed in the cured insoluble matter, which indicated that a dehydration condensation reaction occurred between citric acid and 5-HMF. The preliminary research result of this study shows that sucrose and citric acid adhesive could be synthesized and utilized as adhesive for plywood. The curing behaviour, optimal hot-pressing conditions (such as reducing hot-pressing conditions and increase bond performance) will be further investigated in our further research.

Author Contributions: S.S. and Z.Z. contributed to synthesis, testing, data analysis, and wrote the manuscript. K.U. given the comments and review the manuscript.

Funding: The authors are grateful for the supporting by Natural science fund for colleges and universities in Jiangsu Province (19KJB220010) and Scientific Research Foundation of Nanjing Forestry University (GXL2018013).

Conflicts of Interest: The authors declare no conflict of interest.

\section{References}

1. Pizzi, A. Tannin-based biofoams-A review. J. Renew. Mater. 2019, 7, 477-492. [CrossRef]

2. Pizzi, A. Renewable polymeric adhesives. Polymers 2017, 9, 126. [CrossRef] [PubMed]

3. Mesquita, A.D.L.; Barrero, N.G.; Fiorelli, J.; Christoforo, A.L.; Guerreiro De Faria, L.J;; Rocco Lahr, F.A. Eco-particleboard manufactured from chemically treated fibrous vascular tissue of acai (Euterpe oleracea Mart.) Fruit: A new alternative for the particleboard industry with its potential application in civil construction and furniture. Ind. Crop. Prod. 2018, 112, 644-651. [CrossRef]

4. Iwanaga, S.; Tsuzuki, N.; Kuboyama, H. Impact of the change in raw material supply on enterprise strategies of the Japanese plywood industry. J. For. Res. 2018, 23, 325-335. [CrossRef]

5. Gouveia, S.; Otero, L.A.; Fernandez-Costas, C.; Filgueira, D.; Sanroman, A.; Moldes, D. Green binder based on enzymatically polymerized eucalypt kraft lignin for fiberboard manufacturing: A preliminary study. Polymers 2018, 10, 642. [CrossRef]

6. Stoeckel, F.; Konnerth, J.; Gindl-Altmutter, W. Mechanical properties of adhesives for bonding wood-A review. Int. J. Adhes. Adhes. 2013, 45, 32-41. [CrossRef]

7. Umemura, K.; Inoue, A.; Kawai, S. Development of new natural polymer-based wood adhesives I: Dry bond strength and water resistance of konjac glucomannan, chitosan, and their composites. J. Wood Sci. 2003, 49, 221-226. [CrossRef]

8. Wang, Z.; Zhao, S.J.; Kang, H.J.; Zhang, W.; Li, J.Z.; Zhang, S.F.; Huang, A.M. Reduction of energy consumption of green plywood production by implementing high-efficiency thermal conductive bio-adhesive: Assessment from pilot-scaled application. J. Clean. Prod. 2019, 210, 1366-1375. [CrossRef]

9. Umemura, K.; Kawai, S. Modification of chitosan by the Maillard reaction using cellulose model compounds. Carbohydr. Polym. 2007, 68, 242-248. [CrossRef]

10. Pizzi, A. Bioadhesives for wood and fibres: A critical review. Rev. Adhes. Adhes. 2013, 1, 88-113. [CrossRef]

11. Pizzi, A. Recent developments in eco-efficient bio-based adhesives for wood bonding: Opportunities and issues. J. Adhes. Sci. Technol. 2006, 20, 829-846. [CrossRef]

12. Umemura, K.; Ueda, T.; Munawar, S.S.; Kawai, S. Application of citric acid as natural adhesive for wood. J. Appl. Polym. Sci. 2012, 123, 1991-1996. [CrossRef]

13. Umemura, K.; Ueda, T.; Kawai, S. Characterization of wood-based molding bonded with citric acid. J. Wood Sci. 2012, 58, 38-45. [CrossRef]

14. Umemura, K.; Kawai, S. Development of wood-based materials bonded with citric acid. For. Prod. J. 2015, 65, 38-42. [CrossRef]

15. Umemura, K.; Sugihara, O.; Kawai, S. Investigation of a new natural adhesive composed of citric acid and sucrose for particleboard. J. Wood Sci. 2013, 59, 203-208. [CrossRef] 
16. Umemura, K.; Sugihara, O.; Kawai, S. Investigation of a new natural adhesive composed of citric acid and sucrose for particleboard II: Effects of board density and pressing temperature. J. Wood Sci. 2015, 61, 40-44. [CrossRef]

17. Queneau, Y.; Jarosz, S.; Lewandowski, B.; Fitremann, J. Sucrose chemistry and applications of sucrochemicals. Adv. Carbohydr. Chem. Biochem. 2008, 61, 217-292. [CrossRef]

18. Jarosz, S. The chemistry of sucrose. Pol. J. Chem. 1996, 70, 972-987.

19. Khan, R. Some Fundamental Aspects of Chemistry of Sucrose. Abstr. Pap. Am. Chem. Soc. 1975, 170, 12.

20. Khan, R.; Jones, H.F. Sucrose chemistry-Its position as a raw-material for the chemical-industry. Sugar Ser. 1988, 9, 367-388.

21. Suarez-Pereira, E.; Rubio, E.M.; Pilard, S.; Mellet, C.O.; Fernandez, J.M.G. Di-D-fructose dianhydride-enriched products by acid ion-exchange resin-promoted caramelization of D-fructose: Chemical analyses. J. Agric. Food Chem. 2010, 58, 1777-1787. [CrossRef] [PubMed]

22. Sengar, G.; Sharma, H.K. Food caramels: A review. J. Food Sci. Tech. Mys. 2014, 51, 1686-1696. [CrossRef] [PubMed]

23. Manleyharris, M.; Richards, G.N. A novel fructoglucan from the thermal polymerization of sucrose. Carbohydr. Res. 1993, 240, 183-196. [CrossRef]

24. Quintas, M.; Brandao, T.R.S.; Silva, C.L.M.; Cunha, R.L. Rheology of supersaturated sucrose solutions. J. Food Eng. 2006, 77, 844-852. [CrossRef]

25. Carstensen, J.T.; Van Scoik, K. Amorphous-to-crystalline transformation of sucrose. Pharm. Res. Dordr. 1990, 7, 1278-1281. [CrossRef]

26. Locas, C.P.; Yaylayan, V.A. Isotope labeling studies on the formation of 5-(hydroxymethyl)-2-furaldehyde (HMF) from sucrose by pyrolysis-GC/MS. J. Agric. Food Chem. 2008, 56, 6717-6723. [CrossRef]

27. Popov, K.I.; Sultanova, N.; Ronkkomaki, H.; Hannu-Kuure, M.; Jalonen, J.; Lajunen, L.H.J.; Bugaenko, I.F.; Tuzhilkin, V.I. C-13 NMR and electrospray ionization mass spectrometric study of sucrose aqueous solutions at high pH: NMR measurement of sucrose dissociation constant. Food Chem. 2006, 96, 248-253. [CrossRef]

28. Spectral Database for Organic Compounds. ${ }^{13} \mathrm{C}$ NMR Sucrose (No. 1188CDS-07-029). National Institute of Advanced Industrial Science and Technology (AIST): Japan, 1999. Available online: https://sdbs.db.aist.go.jp/ sdbs/cgi-bin/direct_frame_top.cgi (accessed on 15 September 2019).

29. Kimura, H.; Nakahara, M.; Matubayasi, N. In situ kinetic study on hydrothermal transformation of D-glucose into 5-hydroxymethylfurfural through D-fructose with C-13 NMR. J. Phys. Chem. A 2011, 115, 14013-14021. [CrossRef]

30. Amarasekara, A.S.; Razzaq, A. Mechanism of 1-(1-propylsulfonic)-3-methylimidazolium chloride catalyzed transformation of D-glucose to 5-hydroxymethylfurfural in DMSO: An NMR study. Carbohydr. Res. 2014, 386, 86-91. [CrossRef]

31. Chauvin, M.F.; Megninchanet, F.; Martin, G.; Lhoste, J.M.; Baverel, G. The rabbit kidney tubule utilizes glucose for glutamine synthesis-A C-13 Nmr-study. J. Biol. Chem. 1994, 269, 26025-26033.

32. Spectral Database for Organic Compounds. ${ }^{13} \mathrm{C}$ NMR Sucrose (No. 1995CDS-11-804). National Institute of Advanced Industrial Science and Technology (AIST): Japan, 1999. Available online: https://sdbs.db.aist.go.jp/ sdbs/cgi-bin/direct_frame_top.cgi (accessed on 15 September 2019).

33. Amarasekara, A.S.; Williams, L.D.; Ebede, C.C. Mechanism of the dehydration of D-fructose to 5-hydroxymethylfurfural in dimethyl sulfoxide at 150 degrees C: An NMR study. Carbohydr. Res. 2008, 343, 3021-3024. [CrossRef] [PubMed]

34. Zhang, J.; Weitz, E. An in situ NMR study of the mechanism for the catalytic conversion of fructose to 5-hydroxymethylfurfural and then to levulinic acid using C-13 labeled D-fructose. ACS Catal. 2012, 2, 1211-1218. [CrossRef]

35. Horvat, J.; Klaic, B.; Metelko, B.; Sunjic, V. Mechanism of levulinic acid formation. Tetrahedron Lett. 1985, 26, 2111-2114. [CrossRef]

36. Yamamori, A.; Okada, H.; Kawazoe, N.; Onodera, S.; Shiomi, N. Synthesis of beta-D-fructopyranosyl-(2 -> 6)-D-glucopyranose from D-glucose and D-fructose by a thermal treatment. Biosci. Biotechnol. Biochem. 2010, 74, 2130-2132. [CrossRef] [PubMed]

37. Defaye, J.; García Fernández, J.M. Protonic and thermal activation of sucrose and the oligosaccharide composition of caramel. Carbohyd. Res. 1994, 256, C1-C4. [CrossRef] 
38. Kusumah, S.S.; Umemura, K.; Yoshioka, K.; Miyafuji, H.; Kanayama, K. Utilization of sweet sorghum bagasse and citric acid for manufacturing of particleboard I: Effects of pre-drying treatment and citric acid content on the board properties. Ind. Crop. Prod. 2016, 84, 34-42. [CrossRef]

39. Bichara, L.C.; Lanus, H.E.; Ferrer, E.G.; Gramajo, M.B.; Brandan, S.A. Vibrational study and force field of the citric acid dimer based on the SQM methodology. Adv. Phys. Chem. 2011, 2011. [CrossRef]

40. Surendra, B.S.; Veerabhadraswamy, M. Microwave assisted synthesis of Schiff base via bioplatform chemical intermediate (HMF) derived from Jatropha deoiled seed cake catalyzed by modified Bentonite clay. Mater. Today Proc. 2017, 4, 11968-11976. [CrossRef]

41. Vaz, P.D.; Ribeiro-Claro, P.J.A. C-H …O hydrogen bonds in liquid cyclohexanone revealed by the vC=O splitting and the vC-H blue shift. J. Raman Spectrosc. 2003, 34, 863-867. [CrossRef]

42. Nikolic, G.; Zlatkovic, S.; Cakic, M.; Cakic, S.; Lacnjevac, C.; Rajic, Z. Fast fourier transform IR characterization of epoxy GY systems crosslinked with aliphatic and cycloaliphatic EH polyamine adducts. Sens. Basel 2010, 10, 684-696. [CrossRef]

43. Del Menezzi, C.; Amirou, S.; Pizzi, A.; Xi, X.; Delmotte, L. Reactions with wood carbohydrates and lignin of citric acid as a bond promoter of wood veneer panels. Polymers 2018, 10, 833. [CrossRef] [PubMed]

(C) 2019 by the authors. Licensee MDPI, Basel, Switzerland. This article is an open access article distributed under the terms and conditions of the Creative Commons Attribution (CC BY) license (http://creativecommons.org/licenses/by/4.0/). 